\title{
Beyond the water balance
}

\author{
Jeffrey J. McDonnell
}

\section{The terrestrial water cycle is often assessed annually at catchment scale. But water stored in catchments is poorly mixed, and at timescales often well beyond the calculation of annual water balance.}

O ur quantitative understanding of the terrestrial water cycle dates back to 1674 when the first attempt was made to measure the water balance of a headwater catchment of the River Seine in France ${ }^{1}$. These observations demonstrated that precipitation was sufficient to explain the water carried off by rivers and removed by evaporation. Since then, the annual water balance accounting model for catchments (where inputs of precipitation minus outputs of streamflow and evapotranspiration equals change in storage) has become a fixture in the geosciences. However, much of the water in storage can be isolated in time and space from the water in the stream with a distribution of transit times well beyond the annual cycling. Although streamflow is sufficiently captured by the water balance accounting model, compartmentalization of the parts of the terrestrial water cycle could have a controlling influence on the cycling of solutes, contaminants and nutrients. Rather than continuing to focus on gross inputs and outputs, we need to start thinking about the inventory in our accounting model: the compartmentalized stores and the connections between them.

For hydrologists, some indication of compartmentalization began in the 1970s with the analysis of tritium in streams in the Swiss Alps. There, runoff following snowmelt turned out to be many years older than that year's snowmelt ${ }^{2}$. Subsequently, more and more data showed that the blend of water ages in streamflow could extend from years to decades, with hints of much older water ${ }^{3}$.

Streamflow consists of a mixture of precipitation, soil water and groundwater, but groundwater can be very old and isolated. Indeed, most groundwater deeper than $250 \mathrm{~m}$ is probably comprised of water that recharged more than 12,000 years ago ${ }^{4}-$ a relic of past climates. The deepest wells drilled have revealed waters dating to the Precambrian $^{5}$. Although it is not surprising that groundwater is old and moves slowly, it is surprising how isolated this water can be from the measureable water balance at the Earth's surface, especially in light of work showing that streams can have surprisingly large quantities of young water less than a few

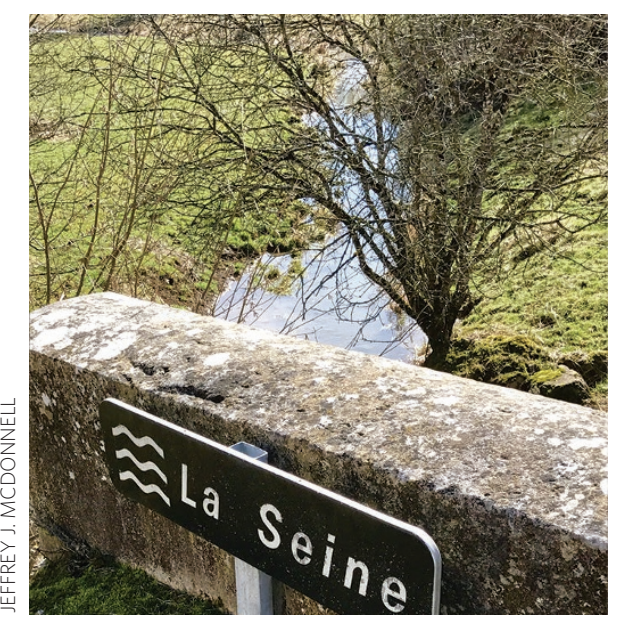

months old ${ }^{6}$. The juxtaposition of very old and very young water presents a challenge to catchment managers as historic contaminants can linger whereas nutrients can flush.

The water removed by evapotranspiration can also be highly compartmentalized. Stable isotope analyses have shown that plants transpire water from soil water pools that do not mix with the mobile waters that recharge groundwater and form streamflow ${ }^{7}$. This has been observed across diverse biomes ${ }^{8}$ as well as from global satellite isotope vapour measurements ${ }^{9}$. Such soil water compartmentalization influences nutrient cycling: for example, mobile soil water tends to be aerobic and thus promotes nitrification; in contrast, less mobile soil water is often anaerobic and promotes denitrification ${ }^{10}$.

The isotopic data point towards a different way of looking at the terrestrial water cycle - one aimed at tracking raindrops and snowmelt rather than just the bulk quantification of input and output (hydrometrics). Numerical models are beginning to explore the links between groundwater flow and transpiration partitioning at scales that include deeper geology $y^{11}$. But these models do not yet include the compartmentalization effects revealed by isotopes. This needs to change. Going forward we need a coordinated multidisciplinary effort to reveal and understand the compartmentalization of water stored in catchments. Asking how geology and biology control the water we see in streams, and using chemistry to help answer these questions may also help remove the artificial boundaries between the fields of hydrogeology, plant physiology, biogeochemistry and soil science.

We have mapped and measured watershed inputs and outputs in catchments for almost 350 years. These studies have served us well in our management of stream flow volumes. But the isotopic composition of water reveals a much more nuanced and complex terrestrial water cycle. Hydrologists need to move beyond their focus on annual water balance hydrometrics and also consider the movement and distribution of water particles in time and space, and the dynamic connections and disconnections of water stored in the ground. This will involve thinking beyond the catchment scale as many water molecules may not obey a defined catchment boundary. Delivering a theoretical framework that includes both flow and the age distribution of these flowing and stored waters is a wicked problem. But c'est très intéressant.

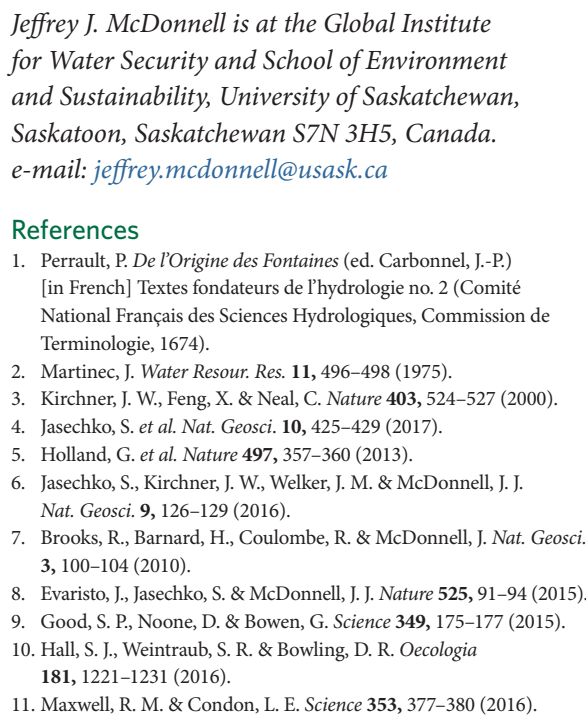

Jeffrey J. McDonnell is at the Global Institute for Water Security and School of Environment and Sustainability, University of Saskatchewan, Saskatoon, Saskatchewan S7N 3H5, Canada. e-mail: jeffrey.mcdonnell@usask.ca

\section{Acknowledgements}

I thank Keith Beven, Markus Weiler, Laurent Pfister, Barbara Sherwood-Lollar, Chris Gabrielli, Kim Janzen and Don Siegel for useful critical comments, and Javime Evaristo and Scott Jasechko for ongoing discussions.

Published online: 29 May 2017 